\title{
Time
}

Society

\section{Time-Spaces of In/dependence and Dis/ability}

\author{
Michael Schillmeier
}

\begin{abstract}
The article highlights the temporal construction of everyday spaces that make up the societal relevance of in/dependences and dis/abilities. Employing an account of empirical philosophy, the article links self-conducted empirical research with philosophical ideas. Introducing Heidegger's notion of 'time-space', the proposed view tries to avoid bifurcating in/dependences and dis/abilities a priori as the effect of given realities. Rather, they appear as highly fragile mediations of heterogeneous elements that make up the times and spaces of emerging in/dependences and dis/abilities. With special reference to 'visual disability', I explore how ordinary acts of 'dealing with money' and 'going shopping' configure multiple 'blind' times and spaces of in/dependence and dis/ability. KEY WORDS blindness; dis/ability; mediation; Heidegger; in/dependence; ready-to-hand; time-space
\end{abstract}

\section{Introduction}

For many people, the question concerning dependence and independence (in/dependence) is vital for experiencing enabling and disabling scenarios (dis/abilities) in the conduct of everyday life. This article highlights the temporal construction of everyday spaces that make up the societal relevance of in/dependences and dis/abilities. The focus on 'time', though, cannot be accomplished by abstracting from 'space'. Rather, employing a temporal conception on in/dependence and dis/ability tries to stress the very practices of 'time- 
spaces' that bring into being the very specific 'times' and 'spaces' of in/dependence and dis/ability in the first place. By doing so, the proposed view tries to avoid bifurcating in/dependences and dis/abilities a priori as the effect given by different abstract realities such as culture and nature, subject and object, individual and society, human and non-human, etc.

I borrow the notion of 'time-space' from the German philosopher Martin Heidegger. Heidegger's 'Zeit-Raum' (Heidegger, 1994, 2000) marks the event that neither refers to 'time' as a mere subjective construction nor 'space' as an objective one. Moreover, the notion of Zeit-Raum cannot be thought of properly as the mere effect of the succession of 'nows'. Hence, Zeit-Räume shouldn't be conflated with Zeiträume, which are measured and countable spaces of time. The relationship between Zeit-Räume and Zeiträume is that of 'mediation' and 'intermediation'. An intermediary 'transports meaning or force without transformation', whereas mediators 'transform, translate, distort, and modify the meaning or the elements they are supposed to carry' (Latour, 2005: 39ff). Clocks and chronographs are a good example to clarify this relation: clock-time mediates time through the spatialization of time into periods, numbers, distances, etc. As clock-time 'time' comes into being through the very absence of time, mere spatial relations define time. In effect, clocks and chronographs become space-giving intermediaries of time. They give space to time as clocktime measurable, calculable, traceable, exact, comparable, dividable, specifiable, etc. Clock-time, then, isn't time but gives time, and in a very specific, spatialized and embodied sense. Through clock-time we have and/or don't have time as seconds, minutes, hours and days wherever we are (Adam, 1995).

Obviously, clock-time time brings us closer to understanding time, especially in modern times. However, clock-time doesn't explain 'the event' Heidegger is talking about; and neither is clock-time 'time' - except, as we have seen, as a specific, globalized intermediary opening up the possibility of and maintaining having modern times. To conflate 'clock-time' or 'space of time' with 'time' or 'time-space' refers to the fallacy of misplaced concreteness, as Alfred N. Whitehead (1978) would say; it abstracts from the event of time itself. Rather, the event refers to the time-space of mediation: 'The event is the self establishing [selbst ermittelnde] and mediating [vermittelnde] middle of Being' (Heidegger, 1994: 75). ${ }^{1}$ The time-space of the event appropriates the openness of the no longer and not yet: it appropriates the absence of presence of timespace and its possible effects. Time-space means 'temporalizing spacing - spacing temporalization [Zeitigendes Räumen - räumende Zeitigung]' (Heidegger, 1994: 261). The event, and this is Heidegger's point, comes into being as appropriation [Ereignis] and disappropriation [Enteignis]. As an event, time-spaces make time and space present and absent in the first place. Time-spaces mediate time into space and space into time. It mediates the motility of time and space. Time spatializes and space temporalizes. 
In such a reading, space and time are heterogeneous entities but as the effect of time-spaces that mediate the durability as well as changeability of what is thought of as temporal or spatial relations. Obviously, for Heidegger it was important to describe the event of Being [Sein] in difference to beings [Seiendes]. This article follows the event of beings (instead of Being) in difference to beings. To be sure, this is not the betrayal of the philosophy of the event but its mediation. The latter unfolds what I like to call empirical philosophy. ${ }^{2}$ This brings me back to the time-spaces of in/dependence and dis/ability.

A temporal reading of in/dependence and dis/ability that focuses on timespace, so my argument goes, leaves ontologically open what is to be understood as 'dis/ability' or 'in/dependence'. In/dependence and dis/ability cannot be treated as fixed beings, but become an event of time-spaces that mediate their multiple realities of in/dependences and dis/abilities instead. Rethinking in/ dependence and dis/ability through the event brings to the fore their being as a 'contestable zone of controversy [strittiger Streitbezirk]' (Heidegger, 1994: 260f). With this in mind, a 'time-space' reading of dis/ability and in/dependence questions any attempt that splits up and mends dis/ability and in/dependence into mere sources of different given realities in order to understand them. In contrast, this article will follow the traces of how in/dependences and dis/abilities come into being through everyday practices. These practices elude an abstract division of in/dependence and dis/ability into pure cultural or natural occasions in time and space.

Obviously there is wide range of becoming in/dependent and dis/abled in everyday life. With special reference to 'visual disability', I explore how ordinary acts of everyday life configure 'blind' times and spaces of in/dependence and dis/ability. Every becoming, as Moser and Law (1999) and Schillmeier (2007a) argue, is specificity in its own right. Different (blind) people live differently in different environments and have different lifestyles; they live alone or with friends or family, they use different props for different reasons, they have different preferences and repugnances, etc. In order to feel independent and being able to do the necessary domestic routines without much distress, bodies, technologies and things have to relate well. To be mobile outside their homes, some blind people manage on their own whereas others depend heavily on relatives and friends. To go out, some use assistive technologies like the white cane or prefer a guide dog. Still, within the complex and highly variable arrangements of societal life, these relations that allow independent living are fragile tempo-material ${ }^{3}$ achievements and may easily turn into dependence and disability (French, 1999; Michalko, 1999; Saerberg, 2007).

Consequently, one may say that when people feel independent or dependent it is the contingent effect of highly specific material relations that have their own rhythms and times, make up their socially relevant spatialities, assemble affects and affectations, visualize (or alter) preferences and old habits, and so on. In 
effect, these relations are delicate achievements and are easily disturbed when bodies, technologies and things do not assemble properly. They may turn good (enabling) achievements into bad (disabling) ones (see Moser and Law, 1999). These highly situated and heterogeneous human and non-human configurations assemble the multiple times and spaces of dis/ability and in/dependence. For the 'visually disabled', dealing with money makes up some crucial scenarios for defining their times and spaces of in/dependences and dis/abilities (Schillmeier, 2007a, 2007b).

\section{Time/Space 'Money'}

Money functions as an intermediary that constantly relates the times and spaces of the world along economic orders. Translating money into things and vice versa, money and money technologies keep economic infrastructures circulating and durable. Money also functions as a mediator - for good and for bad. First of all, the circulation of money enacts the very relation between (calculating) $s u b$ jects and (calculated) objects. Calculating subjects and calculated objects are not intrinsic features of humans and non-humans. Rather, it needs a third element like money which opens up for the times and spaces of calculating subjects and calculated objects: accelerated action and action at a distance (see Simmel, 1989, 1992). Moreover, money mediates the world into fetishes and facts, luxury and debts, peace and war, love and hate, those who have money and those who don't, the rich and the poor, etc. Money creates banks and those who rob them, and - according to Bert Brecht - it remains an open empirical question as to what or who is the bigger delinquent.

At the same time, the fast circulation and distribution of money inscriptions and money technologies mediates the enactment of visual relations that dominate modern cultures (Simmel, 1997). With this in mind, the circulation of money stabilizes modern visual cultures inasmuch as it relies on the visual readability of money inscriptions (Schillmeier, 2007b, 2007c). Money and vision keep modern subjects and objects and their spatio-temporal networks durable. Money not only mediates material, social and moral inequalities, but also fabricates sensory inequalities and in/dependence. In modern times we call it visual disability.

\section{Claire, 53 years old, glaucoma ${ }^{4}$}

Money is so central to our society! And it is the practical day-to-day things like money ... it's just too difficult because it is something we all have to do and there is no way around it. It is depending on issues of trust when you are with your friend, the person in the shop or whoever. Well, you know it is the vulnerability 
blind people feel when actually walking towards a cash point, particularly if they have a white cane . . . I do not feel fine at one of those machines either, particularly at night or in the evening, I tend to look around if somebody is there and you are conscious if there is somebody behind you and if you can't see you feel more vulnerable ... I think the whole issue of money is fraud . . . for me just knowing which is a five-pound note and which is a ten-pound note and coins and things like that. It is a very basic problem, you know, money is very difficult. It is impossible to recognize and to differentiate what is what. It is about the size of the note, about the feel of it and just generally because money is so important to everybody.

\section{Elizabeth, 50 years old, totally blind}

\section{Elizabeth explains how she pays with cash:}

Beforehand I plan how much I will use. Well, I only use five and ten pound notes. That's how I manage it. If in the shop they, know you, they are usually very friendly. They say that's a ten pound note and I say 'that's a ten pound note yes, I know'. I cannot tell the difference from the size. I use a plastic template to measure. I fold them too, half and half again ... You give a note and you get coins as change and you are not sure what it is because there are a lot of people queuing around you. People tend to push. It's a vicious circle. I don't want coins as change but I always get it.

As we can see with Claire and Elizabeth, money not only mediates economic exchange but also mediates social relations. Everyday money transactions require more trust in others since the asymmetry of sensory perception originates the risk of fraud. Due to such sensory asymmetry, people become more vulnerable especially in public spaces. They invite muggers and thieves; the more so if assistant technologies like the white cane symbolizes that the person is blind. Not only do social relations change, but money itself does. It translates from money of and for the sighted to money of and for the blind. However, as we can see, visually attuned money doesn't translate easily into 'blind' money. Currencies differ in their materiality. Money mediates into different materialities (coins, paper money, plastic cards, electronic money, etc.); they also have different colours, shapes, textures, weights, thickness and sizes. To become blind money, different temporal and spatial arrangements have to be mobilized. Blind money practices slow down and lengthen money transactions; blind people plan, select and earmark the money in use. Assistive technologies like templates function as intermediaries to make them translate into blind money. Generally speaking, it is the assemblage of human and non-human configurations enacting blind times and spaces that disrupt, question and alter the presence of visually enacted times and spaces. These configurations also mediate the intermediary 'money' itself; visual money becomes blind money. Such a clash of different regimes of time and space disables when no translation, when no mediation, is possible. Through failed money transactions, blind people become 
disabled. They become visible as blind in visual relations. In that moment, blind people are caught in the event of the no longer and not yet. Money, then, is no longer visual money and not yet blind money. It remains as disabling everyday life.

\section{Rose, 73 years old, age-related macular degeneration}

I prefer cash, it is better for me. I feel more secure with cash and it allows you a more normal life. That's why I prefer cash. If you didn't have cash you have to leave it to somebody else. I need to feel to be a little independent with the money, you know. When I pay, when I go with my daughter shopping I pay myself. I tell her what I want. She takes me to the counter and I pick up my stuff and pay myself. I feel independent and I've got my own money to pay it. You know, the bills come in and I can't see them. I have to leave all that to my daughter to sign it. It's direct debit. All those big bills. But the ordinary everyday things in life I like to be independent. Or, if I want to pay something. You know, if somebody comes for a collection or something. I can't bring my card out and say right I give you fifty pence by card for The Big Issue or something. You know if you live on your own as I do you've got to be independent. There is no way just to rely on other people. You've got try it yourself.

Rose wants to be able to manage money on her own. As we said earlier, handling money is an act that defines calculative subjects and creates a highly specific set of dependent independences as Simmel (1989) has pointed out so well. ${ }^{5}$ The proper use of money makes her feel like a self-acting, calculating and discretionary subject who is able to deal with calculable objects. This is precisely what money relations achieve and necessitate: split subjects and objects. If Rose cannot deal with money, she doesn't feel like a discretionary subject and she appears disabled. Rose, as well as Elizabeth, cannot use 'money' in general. Rose's economic transactions are rather limited to those involving 'cash': she does not deal well with credit cards or with bills. It is her daughter, she says, who takes care of bills. For Rose this does not seem to be extremely problematic as long as she can still be in control of everyday tasks involving money: the supermarket, somebody knocking on the door for a collection, etc. In these situations it is important for her to manage and pay 'with her own money', which, in order to become hers, has to have a material specificity. Cards don't work to pay at the door and bills have to be paid by direct debit signed by her daughter. Big notes are difficult as well since Rose, like many blind people, cannot check the change properly (given the short period of time, they feel vulnerable or an obstacle for others and so on). Blind people can never be sure what they get back; and it is precisely money that has been able to measure precisely what to get back!

Accordingly, Rose's independence is mediated through several dependencies. For her, to manage on her own does not mean to do everything alone. She doesn't mind that her daughter signs big bills since this is the best option any- 
way. She is fine with her daughter walking her around, picking up the products she has asked for, and bringing her and the products chosen to the counter. But once there, she wants to pay on her own. For Rose, the very act of paying at the supermarket's counter defines the agency of paying and excludes all those who have contributed to make her shopping not an individual but collective achievement. Rather, it individualizes Rose's independence. It does not matter that the daughter has helped her continuously and has done all the physical actions of her shopping. The ability to pay marks the whole action as her own - then she feels independent and she is paying 'on her own'.

All those specificities described, so my argument goes, come into being as the effect of the event when money for the sighted translates (or doesn't) into money for the blind. A first result of my investigation, I like to stress that it is the very time-space mediation of a third element like money that opens up for the possibilities of highly specific times and spaces of dis/abilities and in/dependences. We could see how dependencies fabricate independences. Collective dependencies on others - human and non-human alike - configure independent action and abilities. Obviously, collective dependencies may also lure into dependencies and disabilities.

It became very clear that money transactions are dominated by visually regulated rules and routines. As an event, blind practices disrupt, alter and change these practices dramatically. Money practices slow down so significantly that blind people become present as different. Blind practices also visualize the hidden structures of visual everyday money practices, which have been defining the spatial situation as well as the temporalities of action involved. The different materialities, sizes, textures, shapes, weights of the different currencies also play a crucial role in visualizing sensory differences and their temporalities mediating in/dependences and dis/abilities. Furthermore, money appears as a most relevant intermediary in our everyday life - we cannot live without money; 'money is so central to our society', as Claire said. Indeed, money rules the world. It also mediates the world into highly specific relations and entities: value calculating subjects and calculable objects with value. This is why independent money management plays a dominating role for the blind. As I have shown previously, such independence is very much an effect of mediated dependencies. Value objects as money that seem to be endlessly translatable into other things are risky objects since everybody wants to have them. And we have seen that it is much easier to have money, to be with money and to deal with being sighted than being blind. 


\section{Standing Alone: Shopping Experiences and the Simultaneity of Non-Simultaneous Times and Spaces}

\section{Mary, 62 years old, age-related macular degeneration}

The great difficulty is to stand alone. We are going to the supermarket and they have the habit of moving things.

We all sometimes get lost or stuck when we encounter unknown situations. For the blind, living in hegemonic, modern visual infrastructures, this is a much more recurring experience than it is for the majority of sighted others. Mary hints at a typical situation where and why she gets stuck: people in the supermarket tend to move things. Indeed, supermarket strategies tend to change the order of their products from time to time, so as to induce customers to explore the shop and go to areas they normally would not visit. This is meant to make people buy more and different things. For Mary, those strategies appear highly problematic: she does not find the things she was thinking of buying nor does she find possible new products. At that moment, the presence of the supermarket does not translate into the possibility of proper shopping; Mary gets stuck and the displacement of things makes her feel displaced as well.

As we can see, being able to move around and to find one's way involves the synchronicity of memorized spaces and sensed spaces. When Mary finds and identifies the product she intends to buy, the different spaces (memorized and sensed spaces) are simultaneously present and appear as one space where multiple spaces are synchronizing. Memorized and sensed spaces translate into each other; they are time-space, so to speak. But when her memorized space does not connect with the sensed space or vice versa, the lack of synchronicity leaves her stuck in a present past, a future present and a present future. Again, we can see what it means to be caught in the event of the no longer and not yet. Stuck and standing alone, the supermarket's time-spaces are not part of her knowledge anymore. She becomes a stranger in her normal everydayness.

With Heidegger (1993), one can say that the present memorized spatiality ready-to-hand [Zuhanden] (usable and accessible space, where things are known and work) does not translate into the readiness-to-hand of sensed spatialities. Ready-to-hand things assemble Mary's 'blindness' and allow her to feel independent and enable her to move around and do her everyday routines. Present-at-hand [Vorhanden], the time-spaces of the supermarket turn into detached arrangements lying somewhere outside her ready-to-hand memorized knowledge. They make up mere present-at-hand spatialities alienating what is ready-to-hand in her memorized space. Subsequently, the presence of the products she wants to buy appears utterly absent; Mary is caught up in present space full of disconnected and unknown objects. The presence of these absent object-spaces makes her stuck in the past. She cannot connect to the ready-to- 
hand of present space. The non-synchronicity of memorized and sensed spaces visualizes Mary's blindness as highly disabling. Left in the past, she stands alone in the present, feels rather bad and becomes completely dependent on sighted others. She experiences the no longer and not yet.

Simmel (1997) has already pointed out the different social times and spaces that emerge depending on different sensory practices. He argues that the 'sociological mood' of the blind differs from the deaf and the way both - deaf and blind people - relate to the hegemony of visual practices and infrastructures (see also Ree, 1999). For 'the blind person, the other person exists only in succession, in the temporal succession of their utterances'. The 'restless, disturbing simultaneity' of past and present relations as 'it lies revealed in the faces of people elude the blind person' (Simmel, 1997: 114). The blind, according to Simmel's argument, can detach from the ephemeral modern ways of seeing and being seen, because they can withdraw from the natures/cultures of visual relations, whereas the deaf are exposed to them. The blind person lives primarily in non-simultaneous times and spaces which, according to Simmel (1997), 'may be the reason for the peaceful and calm mood, the uniform friendliness towards the surroundings, which is so often observed among the blind' (p. 114). The deaf, the one who sees without hearing, 'is generally much more confused, helpless and disturbed than the one who hears without being able to see' (p. 114). This is partly compensated by the different modes of memorizing through hearing or seeing. We recall better what we have heard than what we have seen, 'despite the fact that what a person has said is irredeemable as such, whereas a person presents themselves to the eye as a relatively stable object' (Simmel, 1997: 114).

The impression one could get is that Simmel simplifies and romanticizes blind practices inasmuch as it is only the 'nature' of vision that allows for the vibrating simultaneity, whereas the blind person remains in the haven of tranquillity given by the non-simultaneous world. The blind appear as the oldfogyish, non-modern counterpart to the velocity of modern (visual) life. However, I think that Simmel's sociological account of the senses shows that different sensory practices mediate different social practices. As we have seen earlier with Elizabeth, Rose and Mary, it seems rather difficult to make any general claims about fixed sources that make visually disabled people 'blind', since it is very much a question of how different 'blind' times and spaces come into being through a multiplicity of mediators. In such a reading, Simmel points very precisely to the issue at stake in this article. It is the co-presence of different sensory and memorizing practices, different temporal practices and the emergence of simultaneous and non-simultaneous spaces that mediate the openness of the human social (Simmel, 1919).

This point is relevant to understanding how Mary needs to sense and access the supermarket's times and spaces when she is faced with the incompatibility between her memory of things and her actual sensory practices of them. The 
permanence of things is granted much more by the mediation of sight than by the other senses. Sighted people are thought to live in the presence of things and persons. To be sure, they also rely on memorized spaces and make the presence visible as a 'seen' practice. The actualization of the present time and space, however, can be done in a much faster and independent way (for instance, by 'having a look around' in the supermarket). Blind practices on the contrary are much more dependent to construct the present through the passage from the past into the future. Blind people, more than sighted people in visual culture, are constantly moved by the possibility of events that change the known into the unknown. Accordingly, blind people have to relate more closely to the absent, the non-present and, indeed, to the invisible. The actualization of past into present is not a process that is smooth and fast - as the 'stop and go' or 'zigzagging' movements of blind people show. Such movements visualize the hard work of constant translation between memorized and sensed/perceived spaces that mediate the emergent time-spaces into new times and spaces as they come into being while sensing and perceiving. Blind practices slow down the temporalities of visual practices and visualize what remains invisible for these visual relations. Most importantly, blind practices show very explicitly that we do not deal simply with the presence of things. Rather, the past and the future have to be translated in multiple ways (depending on, for instance, the different sensory practices involved) into the presence of human practices. They are constantly in touch with the event of the no longer and not yet; it appropriates the absence of presence.

Blindness unravels the presence of memorized space in our daily, visually attuned practices. With this in mind, the past does not refer to the things that happened in the past, as if they were fixed in a self-contained and isolated space that has been left behind. Rather, the past appears where it is not supposed to be: in the present. Blind practices bring to the fore how the past translates into and interferes actively with the present. In this way, blindness discloses the weaving of different pasts (as well as futures), which normally remain hidden within the tempo-spatialities of taken-for-granted visual infrastructures. Blind practices reveal the disruption of the linearity of the flow of things, i.e. from the past into the present and future. Enacted by the known ${ }^{6}$ past and the unknown future, the very act of walking blindly unravels that we always go backwards and forwards in time. We constantly mediate different times and spaces. One can say that the very process of becoming blind 'complexifies' the visual times and spaces in place. It not only makes present the normativity of the 'structural silence' (Seremetakis, 1994) of sighted times and spaces, it also draws attention to the becoming of highly idiosyncratic but mixed times and spaces that synchronize or do not synchronize with other times and spaces.

Blind practices are a good example to question and alter the 'presentism' (Assmann, 2002: 400) of common social constructivism where the past and 
future are mere effects of the present. In our case (where Mary is standing alone), both the past and the future enact the present through the mediation of past and future things. The supermarket's past arrangements come into a present which, for Mary, belongs to the future. These multiple temporal belongings challenge our common (modern) understanding of presence as a mode of nonsimultaneous and simultaneous 'nows' (presentism). Rather, they draw our attention to the power of highly individual, relational effects of time-spaces, which maintain or disrupt, question and alter, the temporalities and spatialities of societal orderings in place.

It also challenges the classical reading of subject-object relations. The things with which we deal in our everyday lives are not mere objects that subjects perceive. Rather, they contribute to the enabling or disabling times and spaces in the conduct of everyday practices. In Mary's case, they emerge as uncertain and vague times and spaces of past and future objects. Caught in the event, the nonaccessible presence of things enacts times and spaces of dependencies that are highly disabling. Hence, it is not about the given subjectivity of sensing or perceiving the objectivity of things. Rather, it is about the mediation of heterogeneous times and spaces that make up human and non-human configurations. It visualizes the compatibility without comparability of time and space as it becomes apparent through the event (time-space):

Each extends the other, but only from the other's position. What the extensions yield are different capacities. In this view, there is no subject-object relation between a person and a tool, only an expanded or realized capability. (Strathern, 1991: 38)

Mary's times and spaces do not synchronize with the times and spaces of the marketing strategies given by the supermarket. Different times and spaces emerge from 'a difference-driven process by which the given is given' (De Landa, 1999: 31). As Gilles Deleuze (2001) argues:

Diversity is given but difference is that by which the given is given . . Every phenomenon refers to an inequality by which it is conditioned ... Everything which happens and everything which appears is correlated with orders of differences. (p. 222)

Mary's story shows the interference of such different temporalities and spatialities. These different realities do not fuse into one, but remain two that are copresent to each other. All of these different times and spaces are real - blind and sighted, actual and virtual alike. ${ }^{7}$ They materialize into Mary's 'blindness' and the supermarket's 'sightedness'. Not only do they co-exist, they become present on their own terms; that is, they are self-referential practices of visual and blind time-spaces. Thus, we have rather complex assemblages of times and spaces that make different times and spaces relate and not relate. To be sure, when things 
are moved in the supermarket, blind as well as sighted people are somehow alienated from the possibility to shop; but, and this is the point, they are affected differently. The supermarket moves things for the sighted and not for Mary!

In effect, Mary stands alone and the supermarket sells nothing. She endangers the supermarket's strategies. Just as the blind beggar who is holding out for money threatens capitalism, so Mary threatens the supermarket's policy when she gets stuck. Moreover, being stuck enacts Mary's disability as a highly visual one and creates the dependence on the sighted. At the same time, the situation actualizes the capacities and skills of 'normal' sighted customers who may have a look around and will (potentially) buy more things.

When Mary gets stuck, she uses specific techniques to overcome her 'blindness':

I stop anybody to ask and I am saying: 'Are you staff?' And they mostly say: 'No love, we are customers'. But I ask anyway: 'Can you tell me what's on that packet? Can you tell me the cooking instruction and can you tell me the expiring date?' and all that sort of thing. By that you keep your independence and you are . . . it is better than sitting down and doing nothing ... I have a good husband; without him I'd be useless, absolutely useless . . . [The white cane] is your best friend, you know? It is a walking stick, a courtesy cane. If you carry a cane people will move away from you. I could not go outdoors without it. We are mates. Without the cane it would be very difficult ...

When stuck, one of her strategies is to enrol others, to make them act with and/or for her. So she tries to synchronize the different visual and blind times and spaces. The husband appears to be very useful in mediating such mixed situations as well. Without her husband's mediation she often feels 'absolutely useless'. In addition, relations with technologies mediate as well: the white cane allows her to keep moving outdoors, ${ }^{8}$ to keep the right distance to others by triggering off courtesy rules. An assistive technology like the cane turns into a 'courtesy cane', a 'mate' that - like her husband - mediates and synchronizes mixed situations and their differing orderings.

Thus, humans and non-humans alike become best friends in mediating her into independences and abilities. Again, we can see that there is not a given source that affects in/dependence and dis/ability. Rather, it is the very process of mediation that enables her to do things and move around. ${ }^{9}$ Mary extends her ready-to-hand embodied practices to heterogeneous others. Thus, the very ability or disability to do things is not a question of independency or dependency. Rather, dis/abilities are effects of heterogeneous relations that actualize dependencies on heterogeneous others.

With this in mind, independences and abilities refer to enabling relations 'without having to look' (Heidegger, 1993: 69). As argued previously, these assemblages unfold the readiness-to-hand of things. According to Heidegger, the associations [Umgang] with ready-to-hand relations are, metaphorically 
speaking, not 'blind'. Rather, they configure the secure and cautious pragmatics of 'care' [Umsicht] that network heterogeneous entities into fitting ones. ${ }^{10}$ Ready-to-hand, mind, bodies, technologies and objects assemble the "handi-network' [Werk] of everyday life. Ready-to-hand, the handi-net-work of things reveals its own 'nature/culture' [Umweltnatur] by mediating humans and nonhumans in highly specific and self-limiting ${ }^{11}$ ways. Moreover, the nature/culture of handi-net-work allows the eventfulness of mediators to become invisible; mediators become intermediaries. By making blind practices work, handi-networks affirm the normativity of blind practices through which 'blind independence' and 'blind ability' are possible. Read-to-hand, these handi-net-works turn invisible; they become black-boxed. This means that ready-to-hand minds, bodies, technologies and objects appear as accessible and connectable in order to live blindness without getting stuck in other practices that enact, or are enacted in, other natures/cultures.

When present-at-hand [Vorhanden] relations and things are disabling the readiness-to-hand of blind practices, it brings to the fore the conspicuousness of the event. Non-conspicuous times and spaces of blind handi-net-works mediate into the conspicuousness and normativity of non-blind times and spaces. This means that minds, bodies, technologies and objects may be present but remain absent for the specific normativity of blind handinet-works: they provoke dependencies and disabilities given by the normativity of non-blind (e.g. visually attuned) natures/cultures instead.

\section{Conclusion}

We have seen how conflicting normativities mediate between the readiness-tohand or presence-at-hand of things and practices. If associations are badly put together, disconnected or displaced from ready-to-hand situations, the very rhythms, the temporalities and spatialities involved are disrupted, questioned and altered. Estranged, humans and non-humans alike become merely presentat-hand. This means, although dependent on each other, humans and nonhumans don't 'understand' each other. They become disabled and dependent entities due to the relations involved: bodies cannot move, courtesy rules are broken, white canes and guide dogs become problematic tools that symbolize blindness, money cannot be read properly as money which won't allow payment to be made, objects become obstacles to run against, minds are not able to think and the senses are unable to feel or decide what is felt.

Such a Heideggerian reading of ordinary acts has tremendous effects on how to approach the issues of dependence or independence and disability or ability. 'Being' dependent or independent and disabled or abled is not given by nature as some(-)thing present-at-hand. Rather, in/dependences and dis/abilities turn 
into a multiple becoming of ready-to-hand and/or present-at-hand times and spaces of human and non-human configurations. Thus, dis/abling practices are fragile passages between the readiness-to-hand and the presence-at-hand of things and practices. They do not refer to mere present-at-hand sources given by mental, sensory or bodily skills on one hand and the properties of objects and technologies on the other. Rather, skills and properties are nothing but modes of mediation that unfold the possibilities of in/dependence and dis/ability. This is precisely what the parlance of the eventfulness of time-spaces is adamant about. The time-space as the event of 'temporalizing spacing - spacing temporalization' makes us aware that there is no such thing as dependence or independence, ability or disability. Rather, we encounter the constant movement between the readiness-to-hand and presence-at-hand of contingent human/non-human objects and relations that articulate (and black-box) the associations of reference of human sociation in everyday life. Enabling relations may easily turn into disabling relationships that again may turn into enabling relations. Such a reading takes the heterogeneous and multiple becomings of human sociation into consideration and 'free[s] us from the dogma that the human sociation which we know is a completely self-evident one' (Simmel, 1997: 114). It brings to the fore the eventfulness of human association and how the normativity of societal orderings (e.g. sighted and blind people) is maintained or questioned and altered.

Following the concept of time-space, readiness-to-hand relations are primordial to present-at-hand relationships (Heidegger, 1993). With it, Heidegger affirms the different times and spaces of beings by the very process of affirmation of time-space itself: times and spaces are the effects of temporalizing spacing and spacing temporalization. Every being is already and always related ready-to-hand to others. Ready-to-hand with others, the event of time-space makes beings become visible (present) to others and invisible (non-present) to themselves. The question, then, of what being is, is not a question of being but a question of the event of associating the different modes of existence (present/absent) that make up the conditions of possibility of being in the first place. By rethinking in/dependence and dis/ability as events, we enter the question of how in/dependence and dis/ability comes into being. Such an interest in the temporality of beings has to be empirical since temporality values the empirical as the only 'contestable zone of controversy' [strittiger Streitbezirk] of beings.

I think an empirical philosophy of time-spaces, as briefly outlined earlier, offers a methodological alternative to traditional disciplinary research that takes either 'the social', or 'the individual', 'the environment' or 'nature', as the sole explanatory power of making the world present. Rather, if we take temporality seriously, those abstract formulas of ordering are disrupted, questioned and altered by the concrete practices of everyday life. Heidegger's philosophy of the event affirms the everyday life of such heterogeneous entities as people and 
things and their properties [Eigentum] by how, when and where they (dis)associate each other. Such properties, for instance, make present 'blind' or 'sighted' practices but, as we have seen previously, only through the other and with other mediators (e.g. money). Mediated properties are too empirical, too diffuse, too messy, too individual, and too complex to be fully explained by an abstract force like, for example, 'nature', 'culture' or 'the social'. Rather, mediated properties object global views of them precisely because they draw people and things together into the 'contestable zone of controversy' of everyday human affairs.

\section{Notes}

1. 'Das Ereignis ist die sich selbst ermittelnde und vermittelnde Mitte, in die alle Wesung der Wahrheit des Seyns im voraus zurückgedacht werden muß.'

2. See Heidegger (1994: 388).

3. On the social relevance of time and its intrinsic relation with the material world, see the work of Barbara Adam (2004a, 2004b).

4. The article draws on qualitative empirical work conducted in the north-west of England (1997-2000). The fieldwork included semi-structured and narrative interviews with 30 blind people (aged from 25 to 90 years). Many of the blind people interviewed were not totally blind; their sight varied from seeing some colours or a small amount of light to seeing only rough edges, black spots and so forth. Only a small number of people were totally blind. Obviously, it also makes a difference if people are congenitally 'blind' or became blind later in life. But this is just one of many specificities that make up the complexities of people's blindness. At this point, I wish to thank all the blind people I have met during my fieldwork.

5. Let us not forget that children are slowly introduced to money, and it takes them a while to obtain permission from proper calculative agents to use it on their own and without surveillance. Elderly people have difficulties again in dealing with the timespaces of how currencies are used.

6. The past also becomes unknown by forgetting. It can affect good and bad passages as well. It may give time and space for the 'future' but it may estrange people from the 'presence' of the world (as it is the case with dementia).

7. With Mary, the virtual past and future are real. 'The virtual is fully real in so far as it is virtual . . . The actualisation of the virtual . . always takes place by difference, divergence or differentiation. Actualisation breaks with resemblance as a process no less than it does with identity as a principle. Actual terms never resemble the singularities they incarnate. In this sense, actualisation or differentiation is always genuine creation' (Deleuze, 2001: 208-212). See also Bergson (1948, 1991, 1998).

8. Obviously, the white cane does not work for all visually disabled people. For many of them, the white cane makes them feel independent and symbolizes or visualizes their disability in the first place. For others the white cane is an 'invitation to muggers' (see Schillmeier, 2007b, 2007c). I will discuss this point later in the article.

9. On mediation, see Callon (1986, 1991, 1998) and Latour (1986, 1994, 2005).

10. Heidegger uses 'sightedness' and 'blindness' as metaphors for practices that enable or disable. Obviously, it is not about the everyday practices of blindness at all, since 
they can be - in Heidegger's parlance - 'sighted' and 'blind'. Hence, in order to address the very enabling and disabling practices of blind people I will use the conceptual division between ready-to-hand and present-at-hand to avoid any misreading.

11. These limits are not fixed boundaries. They are constantly changing, as does the related 'Umweltnatur'.

\section{References}

Adam, B. (1995) Time Watch. The Social Analysis of Time. Cambridge: Polity Press. Adam, B. (2004a) Time. Cambridge: Polity Press.

Adam, B. (2004b) 'Memory of Futures', KronoScope 4: 297-316.

Assmann, J. (2002) 'Nachwort', in E. Esposito (ed.) Soziales Vergessen. Formen und Medien des Gedächtnisses der Gesellschaft [Social Oblivion. Forms and Media of Social Memory], pp. 400-14. Frankfurt/Main: Suhrkamp.

Bergson, H. (1948) Denken und Schöpferisches Werden. Aufsätze und Vorträge [Creative Evolution]. Meisenheim am Glan: Westkulturverlag/Anton Hain.

Bergson, H. (1991) Matter and Memory. New York: Zone Books.

Bergson, H. (1998) Creative Evolution. Mineola, NY: Dover Publications.

Callon, M. (1986) 'Some Elements of a Sociology of Translation: Domestication of the Scallops and the Fishermen of St. Brieuc Bay', in J. Law (ed.) Power, Action and Belief: A New Sociology of Knowledge?, pp. 196-233. London: Routledge and Kegan Paul.

Callon, M. (1991) 'Techno-Economic Networks and Irreversibility', in J. Law (ed.) A Sociology of Monsters. Essays on Power, Technology and Domination, pp. 132-61. London: Routledge.

Callon, M. (1998) The Laws of the Markets. Oxford: Blackwell.

De Landa, M. (1999) 'Deleuze, Diagrams, and the Open-Ended Becoming', in E. Grosz (ed.) Becomings. Explorations in Time, Memory, and Futures, pp. 29-42. Ithaca/ London: Cornell University.

Deleuze, G. (2001) Difference and Repetition. London: Continuum.

French, S. (1999) 'The Wind Gets in My Way', in M. Corker and S. French (eds) Disability Discourse, pp. 21-7. Buckingham: Open University Press.

Heidegger, M. (1993) Sein und Zeit [Being and Time]. Tübingen: Max Niemeyer.

Heidegger, M. (1994) Beiträge zur Philosophie (Vom Ereignis) [Contributions to Philosophy]. Frankfurt am Main: Klostermann.

Heidegger, M. (2000) Zur Sache des Denkens [On Time and Being]. Tübingen: Max Niemeyer.

Latour, B. (1986) 'Visualization and Cognition: Thinking with Hands and Eyes', Knowledge and Society: Studies in the Sociology of Culture, Past and Present 6: 1-40.

Latour, B. (1994) 'Pragmatogonies. A Mythical Account of How Humans and Nonhumans Swap Properties', American Behavioral Scientist 37(6): 791-808.

Latour, B. (2005) Re-assembling the Social. An Introduction to Actor-Network-Theory. Oxford: Oxford University Press.

Michalko, R. (1999) The Two-In-One. Walking with Smokie, Walking with Blindness. Philadelphia, PA: Temple University Press.

Moser, I. and Law, J. (1999) 'Good Passages, Bad Passages', in J. Law and J. Hassard 
(eds) Actor Network Theory and After. Sociological Review Monographs, pp. 196220. Oxford: Blackwell.

Ree, J. (1999) I See a Voice. Language, Deafness and the Senses: A Philosophical History. London: Harper Collins.

Saerberg, S. (2007) 'Geradeaus ist Einfach Immer Geradeaus'. Eine Lebensweltliche Ethnographie Blinder Raumorientierung ['Straight Ahead is Straight Ahead'. A Lifeworld Ethnography of Blind People and the Perception of Space]. Konstanz: UVK.

Schillmeier, M. (2007a) 'Politik des Behindert-Werdens. Behinderung als Erfahrung und Ereignis [The Politics of Becoming Disabled. Disability as Experience and Event]', in W. Schneider and A. Waldschmidt (eds) Disability Studies, Kultursoziologie und Soziologie der Behinderung. Erkundungen in einem Neuen Forschungsfeld [Disability Studies, Cultural Sociology, Explorations of/in a New Research Field], pp. 79-99. Bielefeld: Transcript.

Schillmeier, M. (2007b) 'Dis/abling Spaces of Calculation. Blindness and Money in Everyday Life', Environmental and Planning D: Society and Space 25(4): 594-609.

Schillmeier, M. (2007c) 'Dis/abling Practices: Rethinking Disability', Human Affairs 17(2): 195-208.

Seremetakis, N. C. (1994) The Senses Still. Perception and Memory as Material Culture in Modernity. Chicago, IL: University of Chicago Press.

Simmel, G. (1919) Philosophische Kultur [Philosophical Culture]. Leipzig: Kröner.

Simmel, G. (1989) Philosophie des Geldes [Philosophy of Money] (Collected Works, Vol. 6). Frankfurt am Main: Suhrkamp.

Simmel, G. (1992) Aufsätze und Abhandlungen 1894-1900 [Papers and Essays 1984-1900] (Collected Works, Vol. 5). Frankfurt am Main: Suhrkamp.

Simmel, G. (1997) 'Sociology of the Senses', in D. Frisby and M. Featherstone (eds) Simmel on Culture, pp. 109-20. London: SAGE.

Strathern, M. (1991) Partial Connections. Lanham, MD: Rowman and Littlefield.

Whitehead, A. N. (1978) Process and Reality. An Essay in Cosmology. Corrected Version. London: The Free Press.

MICHAEL SCHILLMEIER teaches Sociology, Science and Technology Studies (STS), Disability Studies and Empirical Philosophy at the Department of Sociology at Ludwig-Maximilians-University, Germany. He received his PhD from Lancaster University, UK. He mainly writes on the material dynamics of societal ordering and change, cosmo-political events, on bodies/senses and dis/ability, on the societal relevance of objects and the heterogeneity of the social. ADDRESS: Institut für Soziologie, LudwigMaximilians-Universität München, Konradstrasse 6, 80801 München, Germany.

[email: m.schillmeier@lmu.de] 